\title{
STUDY ON A CONTROL SYSTEM OF HYDRAULIC LIFTING AND MOVING RAIL EQUPMENT TEST BENCH
}

\author{
Zhengyao YI, Wei XIONG and Haitao WANG \\ Transportation and Logistics Engineering College, Dalian Maritime University \\ 1Linghai Road, Dalian,116026, China \\ (E-mail: wht810@vip.sina.com)
}

\begin{abstract}
A hydraulic lifting-moving-rail equipment test bench is designed, which can lift and move the rail for examining and repairing. The loading system is an electric-hydraulic servo control system. The original control strategy has some disadvantages, such as overshoot and slow response, which severely effect dynamic performance and test precision of system. According to the fuzzy control theory, the fuzzy-PID controller was designed by using ordinarily PID controller method. Experiments show that the performance of fuzzy-PID control system is obviously improved.
\end{abstract}

\section{KEY WORDS}

Hydraulic lifting-moving-rail equipment, Test bench, Electric-hydraulic servo control, Fuzzy-PID controller

\section{INTRODUCTION}

In recent years, with the rapid development of rail transportation in China, more high-speed and heavy-load trains are utilized. It is necessary to maintain railway in a good condition. Hydraulic lifting-moving-rail equipment which is used to raise and toggle rail for examination is an important device for railway. Its quality plays a critical role in maintenance and repair of railway. Thus, the functional detection of hydraulic lifting-moving-rail equipment is needed.

The hydraulic test bench is utilized to test output force of hydraulic lifting-moving-rail equipment. The process of pressurizing and maintaining is controlled by an electro-hydraulic servo-controller. With the influence of flow rate, pressure difference of orifices, inertia of oil and piston rod, leak of oil and lag of loop, there are many disadvantage of existing control strategies such as instability of system, large overshoot and slow response, which affects the dynamic performance and detection precision of system seriously [1-2]. So, it is necessary to find optimized control strategies. However, it is difficult to get good experimental results by using traditional PID control methods. Fuzzy control is used to adapt the change of system parameters in order to control the system steadily and accurately. But fuzzy control fails to make upper precision for its own features [3]. Therefore, fuzzy -PID control strategy which combines the merits of fuzzy control and PID control is adopted in this paper.

\section{STRUCTURE AND CONTROL PRINCIPLE OF THE BENCH}

\section{Hydraulic Lifting-moving-rail Equipment}

A model of hydraulic lifting-moving-rail equipment is shown in Figure 1. With the piston rod of cylinder extension by loading oil tank which connected with cylinder, the lifting wheel can lift and move the rail, and maintain the rail in a certain high for 3 minutes. It is necessary to detect the hydraulic lifting-moving-rail equipment due to its leak and coecibility of the oil and its quality. 


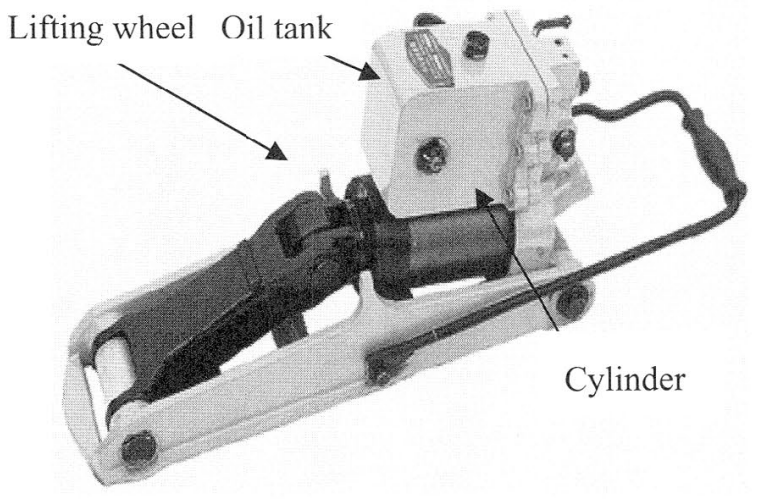

Figure 1 Hydraulic lifting-moving-rail equipment

\section{Hydraulic System Principle of the Test Bench}

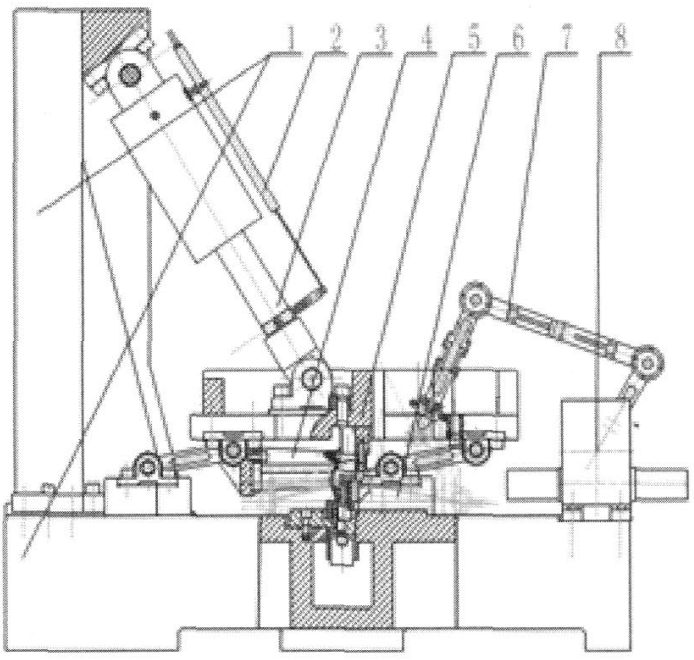

1. Frame 2.Displacement sensor 3.Loading cylinder 4. Press plate 5. Push plate 6 .Hydraulic lifting-moving-rail equipment 7.Drive staff 8 . Tilting cylinder

Figure 2 Structure of the test bench

The structure of the test bench is shown in Figure 2 and the hydraulic system principle of the test bench is shown in Figure 3. The cylinder piston rod controlled by "J" change valve and detected by displacement sensor is connected with the press plate and push plate, whose function is loading lifting-moving-rail equipment. The tilting cylinder controlled by " $Y$ " change valve is connected with the drive staff, whose function is rising cylinder piston rod of lifting-moving-rail equipment. The electromagnetic relief valve plays a role in adjusting the pressure of system loop.

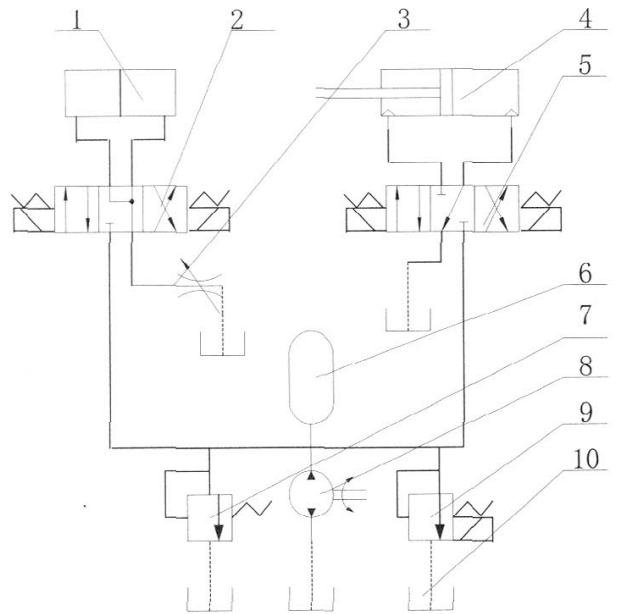

1. Tilting cylinder2. "Y" change valve 3 . Flow regulating valve 4 . Loading cylinder 5 . "J" change valve

6.Accumulator7.Safety valve8. Hydraulic pump

9.Electromagnetic relief valve10.Oil tank

Figure 3 Hydraulic system principle of the test bench

\section{Control System Principle of the Bench}

Test bench of hydraulic lifting-moving-rail equipment is a control system which tests load actively. It is a closed loop system which is mainly comprised of amplifier, magnetic proportional overflow valve, hydraulic cylinder and pressure sensor, etc. Load control system is shown in Figure4.

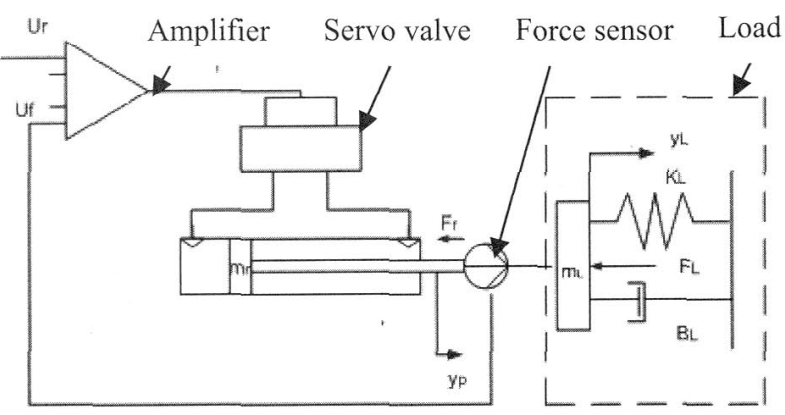

Figure 4 Control system principle of the test bench

\section{DESIGN OF FUZZY CONTROLLER}

\section{Principle of Fuzzy PID Control}

Traditional PID control is precise and steady. However, it can't adapt the change of parameters. Fuzzy control system is better in dynamic condition, but it can't achieve steady precision; sometimes cause limit cycles oscillations. Thus, fuzzy-PID linear control is proposed to combine the merits of traditional PID and fuzzy 
control system [3]. Its principal is illustrated in Figure5.

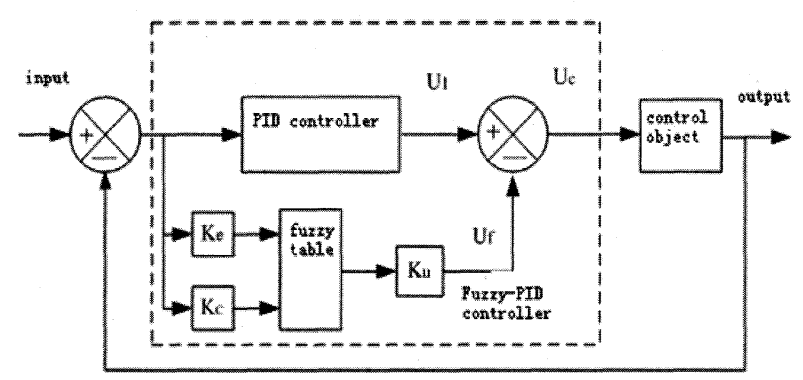

Figure 5 Fuzzy PID complex controller

The main principal of fuzzy PID linear control is explained as following: when system error $(e)$ enter into $<0>$ grade and output $\left(u_{f}\right)$ of fuzzy controller is zero, the output $\left(u_{c}\right)$ of controller is equal to the output $\left(u_{1}\right)$ of linear PID, namely $u_{c}=u_{1}$. The system is totally adjusted by linear PID controller. On the other hand, when system error is out of $<0>$ grade, output $\left(u_{f}\right)$ of fuzzy controller is not zero and output $\left(u_{c}\right)$ of controller is the combination of the output $\left(u_{f}\right)$ of fuzzy controller and the output $\left(u_{1}\right)$ of linear PID, namely $u_{c}=u_{f}+u_{1}$. The system is drove more efficiently and obtains better steady dynamic performance [5].

Design of Fuzzy Control Rule Table on the Bench

The control rule is showed in table 1 .

Table 1 Fuzzy control rule

\begin{tabular}{|c|c|c|c|c|c|c|c|c|}
\hline & \multicolumn{8}{|c|}{ The change of pressure error $\mathrm{CE}$} \\
\hline \multirow{8}{*}{$\begin{array}{c}\text { Pressure } \\
\text { error E }\end{array}$} & $\mathrm{E} / \mathrm{CE}$ & NB & $\mathrm{NM}$ & NS & 0 & PS & PM & PB \\
\hline & NB & $\mathrm{PB}$ & $\mathrm{PB}$ & $\mathrm{PB}$ & PB & PM & 0 & 0 \\
\hline & NM & $\mathrm{PB}$ & $\mathrm{PB}$ & PB & PB & $\mathrm{PM}$ & 0 & 0 \\
\hline & NS & PM & PM & PM & PM & 0 & NS & NS \\
\hline & N0 & PM & $\mathrm{PM}$ & PS & 0 & NS & NM & NM \\
\hline & PB & PM & PM & PS & 0 & NS & NM & NM \\
\hline & PS & PS & PS & 0 & NM & NM & NM & $\mathrm{NM}$ \\
\hline & PM & 0 & 0 & NM & NB & NB & NB & NB \\
\hline
\end{tabular}

When system error is big negative and the variation is negative, the trend of error increases. Therefore, the big positive variation of controlled quantity is selected in order to get rid of the big negative error and restrain the trend of error to be big. When system error is negative and the variation is positive, the trend of error decreases. Therefore, the small controlled quantity is selected in order to get rid of the negative error and restrain overshoot. When system error is big negative and the variation is small positive, the mid positive variation of controlled quantity is selected. When system error is big negative and the variation is big positive or mid positive, the increase of controlled quantity is not suitable, or else it will bring overshoot. Therefore, the $<0>$ grade controlled quantity is selected. Obviously, when system error is mid negative, the choice of controlled quantity is the same as the big negative. Evidently, when system error is small negative, the system is approach steady.

\section{EXPERIMENTS}

\section{Interface of Fuzzy PID Controller}

Based on fuzzy-PID control strategy and discrete PID control equation, the fuzzy-PID control system is designed by Visual Basic which is shown in Figure6.

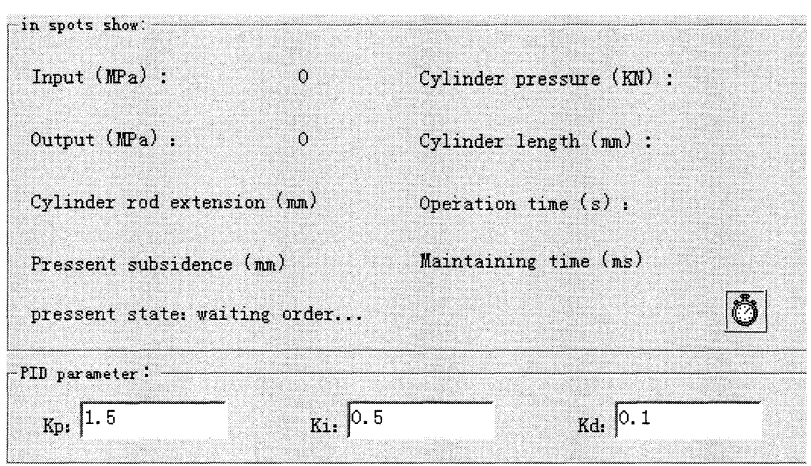

Figure 6 Fuzzy PID control interface

\section{Results}

Three response curves which are respectively drawn according to original ratio control, PID control and fuzzy-PID control are shown in the following diagram.

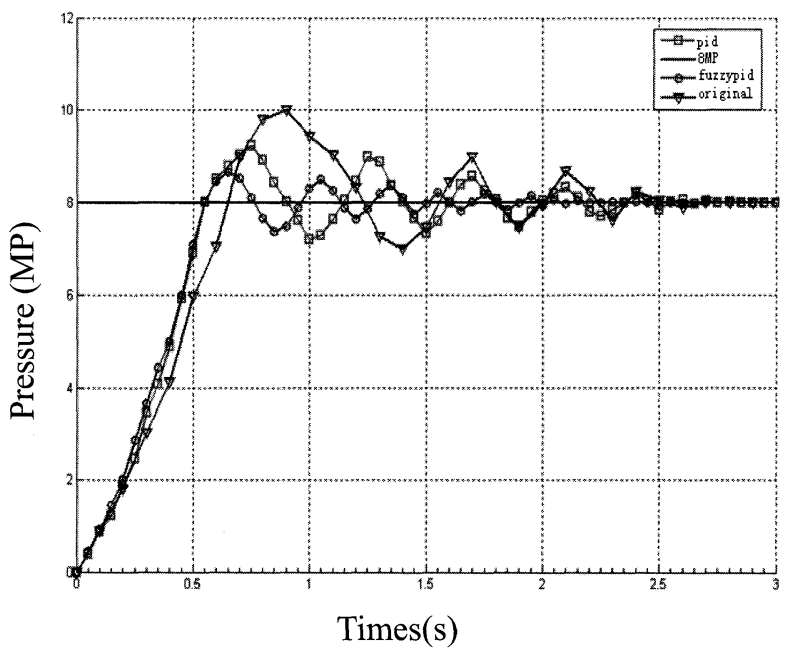

Figure 7 Three time response curves

As illustrated in Figure 7, if the test system of test bench adopts original control, its overshoot is so bigger $(25.6 \%)$ that it is unstable, and response time exceeds 3 seconds and rise time is 0.9 seconds. The precision of 
system is lower. If the test system utilizes PID control, it is relatively stable and its overshoot is $16.4 \%$, and response time is 2.65 seconds and rise time is 0.75 seconds. With the test system of fuzzy-PID control, it is stable and its overshoot is reduced obviously (lower than $8.7 \%$ ), and response time is 2.25 seconds and rise time is 0.65 seconds. The system precision reaches $1 \%$ (lower than 2\%), which meets demand of the system.

\section{CONCLUSIONS}

(1) The overshoot of fuzzy-PID control system is minimum compared to other two control strategies;

(2) Compared to other two control strategies the response time of fuzzy-PID control is shorter than other two control strategies, but only little difference;

(3) The rise time of fuzzy-PID control is the shortest.

\section{REFERENCES}

1. Ke LI, Mannan M.A. and Mingqian XU. Electro-hydraulic Proportional Control of Twin-cylinder Hydraulic Elevators [J]. Control Engineering Practice Volume, 2001, 4, pp.367-373.

2. Bonchis,A. and Corke, P.I., Variable Structure Methods in Hydraulic Servo Systems Control [J] Automatica, 2001, pp.589-595.

3. Lee S.Y., Fuzzy Controller for an Electro-hydraulic Fin Actuator Using Phase Plane Method [J]. Control Engineering Practice, 2003, 11, pp.697-708.

4. Voda A., and Landu LD., A Method for the Auto-calibrition of PID Controller [J]. Automatic, 1995, pp.41-53.

5. Sugeno M., and TakahiroY., A Fuzzy Logic-based approach to Aualitative Modeling. IEEE Trans on Fuzzy System, 1993, pp.7-31. 